\title{
On the Unexpected Consequences of Perspective Taking: Influence of Spatial Perspective Rotation on Infra-humanization
}

\author{
Alicja Gniewek, Agnieszka Wojnarowska, Anna Szuster \\ Faculty of Psychology, Warsaw University, Warsaw, Poland
}

\begin{abstract}
This research examined spatial perspective taking and its effect on the perception of other people's emotionality. Adopting the perspective of another person is considered an important factor enhancing interpersonal and intergroup relations. However, it requires conscious effort and reflection. Therefore, the aim was to determine whether rotating spatial perspective places demands on cognitive resources, thereby affecting automatic perception of other people's emotionality.

Inspired by previous research, the authors developed the software used in this study. Participants were prompted to move objects on a bookshelf according to the directions of a person standing either on the opposite side of the bookshelf or next to them, on the same side. Using an infra-humanization scale, participants rated their own emotions and those of the person whose perspective they assumed.

The results confirmed the hypotheses. Firstly, the need for perspective rotation resulted in decreased performance of the task (lower accuracy and longer time to complete). Secondly, perspective rotation conditions amplified the effect of infra-humanization, i.e., the partner was seen by the participant as less capable of experiencing uniquely human emotions. We can infer that the change of spatial perspective consumed cognitive resources, thereby promoting a simplified and automatic mode of perception.
\end{abstract}

Key words: perspective taking, infra-humanization, social perception, spatial perspective rotation, social vs. spatial perspective taking

\section{Introduction}

The aim of the study is to explore the phenomenon of spatial perspective taking and its regulatory consequences for social function-

Acknowledgments

Funding for the study was provided by the University of Warsaw, Faculty of Psychology: author Alicja Gniewek has received research grant DSM 114200/ 2016; author Anna Szuster has received BST 174415/ 2015 .

Correspondence concerning this article should be addressed to Alicja Gniewek, Faculty of Psychology, 5/7 Stawki St., Warsaw, 00-183, Poland. E-mail: alicja.gniewek@psych.uw.edu.pl

Received February 7, 2018 ing of individuals and, specifically, for the infra-humanization effect. The researchers focused on one of the symptoms of infra-humanization that is manifested by the person's denying other people (those belonging to a different social category) the ability to experience specifically human emotions (Leyens, 2000).

Perspective taking is a complex and multidimensional concept. Social perspective taking (i.e., cognitive empathy, emotional intelligence) and spatial (visual and visuospatial) perspective taking are two different, yet interwoven, aspects and manifestations of this phenomenon. Beneficial consequences of social perspective taking for social functioning of individuals have been demonstrated in numerous studies. Their results consistently indicate a positive impact of perspective taking on inter- 
personal relationships: A dispositional level of perspective taking decreases automatic negative attitudes toward others (Szuster, Gniewek, \& Wojnarowska, 2016) and within intergroup relations (Crisp \& Hewstone, 2006; Drogosz, Bilewicz, \& Kofta, 2012), and reduces negative behaviors (e.g., peer violence: Chalmers \& Townsend, 1990; Chandler, 1973) and cyberbullying (Barlinska, Szuster, \& Winiewski, 2013, 2015). Perspective taking has also been found to reduce age-related stereotyping (Galinsky \& Moskowitz, 2000).

However, research exploring the influence of the spatial aspect of perspective taking on social perception (e.g., in the phenomenon of infra-humanization) is scarce. Few researchers have studied the effects of focusing the observer's attention on the other person's spatial perspective. We assume that the consequences of focusing on these two aspects of perspective taking (social and spatial) could prove to be quite diverse.

\section{The Phenomenon of Spatial Perspective Taking}

The very concept of perspective taking assumes the presence of an object viewed from multiple standpoints (Moll \& Tomasello, 2007). Social perspective taking is defined as a process through which the perceiver discerns the thoughts, feelings and motivations of one or more persons. It comprises appreciating the point of view of people who represent different values and attempting to understand how a given situation is perceived by others (Gelhbach, 2004). Spatial perspective taking, on the other hand, is a process through which the beholder perceives how some physical objects look from different points of view (meaning different spatial positions).

It seems that the two aspects of this process - the spatial and the social - are intertwined. It is even manifested in language itself, in such expressions as "point of view", "to view something from a different standpoint", etc. They show how one's focusing on the situation of another person is actually related to the terms that are characteristic of the visual perspective (Lakoff \& Johnson, 1980; Erle \& Topolinski, 2015). They both also perform a similar function, i.e. they describe a situation (in its psychological or visual aspect) in relation to another, concrete person or object.

However, numerous other studies point to the distinctness and specificity of spatial perspective taking (Libby \& Eibach, 2011). Their results indicate that social perspective taking could be an isolated cognitive process, both on the neuronal (Ruby \& Decety, 2001; Ruby \& Decety, 2003; Ruby \& Decety, 2004), as well as behavioral level (Kozhevnikov \& Hegarty, 2001; Hegarty \& Waller, 2004), whereas spatial perspective taking is devoid of any social content (Surtees, Apperly, \& Samson, 2013).

The studies conducted by Fiske and his colleagues show different consequences of social and spatial perspective taking (Fiske, Taylor, Etcoff, \& Laufer, 1979). Assuming a spatial (visual) perspective causes the elements of a given situation to be remembered much better in comparison to the situation when a social (empathy arousing) perspective is adopted. Also, in the latter condition, the cause-effect attribution takes place more frequently.

The "bottom-up" path is specific to information processing, in which the visual perspective is taken, whereas the "top-down" path determines the processing channel when the social perspective taking occurs. Self-awareness and the awareness of other persons underlie the very phenomenon of perspective taking. On this abstract level, a psychological sense of understanding the other is being generated (Davis, Conklin, Smith, \& Luce, 1996; Cialdini, Brown, Lewis, Luce, \& Neuberg, 1997). On the other hand, activation of the visual, spatial perspective occurs as a result of focusing the 
person's attention on characteristic features of his or her surroundings, on a direct simulation and on creating concrete representations that enable the person to "step into the shoes" of the other. The thesis of "the bottom-up" type of processing in case of the visual perspective taking is also supported by findings of research on spatial embodiment. The visual perspective researchers emphasize that the body's posture, when consistent with an angle at which perspective is being taken, strongly influences the accurateness and speed at which it is adopted (Kessler \& Thomson, 2010; Kessler \& Rutherford, 2010).

One of the first paradigms dealing with the spatial, visual ability of perspective taking is the so-called Mountain Task (Piaget \& Inhelder, 1956). A child, sitting in front of a model of a mountain, is asked to describe what a doll seated on the opposite side can see (Piaget, 1955). It turns out that children under the age of 7 are unable to effectively decentrate and mentally rotate the spatial perspective. The core of the task is to assume visual and spatial perspective (Flavell, Green, Flavell, Watson, \& Campione, 1986; Kessler \& Rutherford, 2010; Michelon \& Zacks, 2006) and not to engage in social representations of what the other party is thinking or feeling. Developing the ability to perceive points of view within space (in the literal sense of the word) is the very measure of decentration and, at the same time, the basis for social perspective taking (Hamilton, Brindley, \& Frith, 2009).

The spatial aspect of perspective taking appears to have a significant impact both on the person's further cognitive functioning as well as his/her social activity, i.e. orientation and attitudes towards others. The classic research by Storms (1973) demonstrated the significance of spatial perspective rotation for reducing the actor-observer asymmetry. When the actor's observation from the observer's own spatial perspective generated an actor-observer effect, placing the actor at the position of the observer proved sufficient not only for reducing but also for reversing that effect (Storms, 1973). The effect was caused not by the observer's mental rotation of the spatial perspective, but by the actual physical change of the observer's location.

Other consequences of spatial perspective rotation were demonstrated in the results of research conducted by Keysar and colleagues (Keysar, Barr, Balin, \& Brauner, 2000). Theyused a communication game asking participants to move objects around on an array with slots in accordance with the instructions. Several objects were placed in the slots, most of them visible from both sides of the array. The participant sat on one side, and the experimenter's assistant, who was giving instructions, on the other. Participants were told that some slots on the array would be blocked so that the person giving instructions would not see the objects placed in them. The key role in the experiment was played by the same objects but of different sizes: a medium-sized and a large candle. The smallest or the largest of these objects was placed on the shelf that was occluded from the person giving instructions - e.g., the smallest candle. The task of the participant was to move the object as instructed. The instructions were designed so that the participant would have to take into account the perspective of the other person (e.g., the experimenter's assistant might say "Move the smallest candle one slot down", while the smallest candle seen from the assistant's perspective was the medium candle from the participant's perspective).

The results showed that participants not only made more mistakes, but spent significantly more time performing the task than those in the control condition (where both parties had unobstructed view of all shelves) looking at the "confounding" objects blocked from the person on the opposite side (e.g., at the smallest candle seen from their perspective and occluded from the person giving directions), before fi- 
nally reaching for the right object (the mediumsized candle visible to the person on the other side). The authors explained this difference in terms of the egocentric strategy, pointing out that people orient themselves in that kind of spatial situation by starting from "egocentrism" and focusing on their own point of view because it is easily and readily accessible. This approach is then corrected in subsequent steps by using more cognitive resources, which enable individuals to view the situation from a different perspective and adjust their actions accordingly. Thus, the heuristic, effortlessly available content (our own point of view in this case) dominates the field of vision, potentially leading to errors in task performance. The need to rotate spatial perspective mobilizes cognitive resources, as well as the self-control required to inhibit the primary response following the "incorrect", but permanently available, perspective. This proves that spatial perspective taking engages a significant amount of attention and control resources.

Thus, there seems to be every reason to believe that activation of spatial perspective taking in which cognitive resources are engaged may intensify distortions related to automatic categorization processes, including the infrahumanization effect.

\section{Infra-humanization - The Result of Simplified Cognitive Strategy}

A number of studies have shown that people tend to perceive the quality of being human as an essential feature of their in-group, while denying that same quality to the members of an out-group. The results of research (RodriguezTorres et al., 2005) have shown that along with intelligence and the ability to think and use language, another vital criterion of being a human, is the ability to experience secondary emotions, which, as opposed to primary emotions, are considered specific to humans and remain in- accessible to animals (Ekman, 1992; Sroufe, 1979). In a series of studies, researchers proved that "strangers" are indeed less liked and considered less intelligent and creative, but also perceived as less capable of experiencing typically human emotions (such as pride or hatred - Paladino et al., 2002). This is a very subtle process. It does not consist of overtly denying "strangers" (out-group members) their belonging to the human species, yet it contributes to developing an opinion that, as human beings, they are less worthy and are devoid of substance and depth. One of the manifestations of subtle infra-humanization is the asymmetrical attribution of emotions recognized as typically human (secondary) and those experienced by people and animals alike (primary). While the intensity of experiencing primary emotions is not a differentiator between in-group and outgroup, secondary emotions are more readily attributed to members of one's in-group (Leyens et al., 2001). Thus, the quality of being human is not something permanent and inalienable, but rather, a dynamic dimension of comparisons. The phenomenon of infra-humanization has been shown to be universal (Demoulin et al., 2009). Rather than denying other people's humanity, it involves relative differentiation in ascribing uniquely human traits to one's fellows and strangers. An out-group can still be seen as human, although to a lesser degree than the in-group. Infra-humanization has been shown to be independent of negative attitudes toward strangers: It affects both positive and negative emotions. It emerges between groups even in the absence of objective reasons [e.g., lack of conflicting interests between French and Spanish students or between students from continental Spain and the Canary Islands, as in the research conducted by Leyens et al. (2001)]. Moreover, it is not limited to relations with the least favorably perceived out-groups: The bestliked ones also tend to be seen as less human (Vaes \& Paladino, 2010). The sole prerequisite 
for its emergence is an act of categorization. Infra-humanization is an implicit, automatic process. People are not aware of applying inconsistent standards when assessing the emotional functioning of others. The effect is revealed with the use of implicit cognition measures, such as the Implicit Association Test (IAT). The time of categorization of secondary emotions in the "US" category was found to be shorter than in the case of the "OTHERS" category (Leyens et al., 2001; Boccato et al., 2007).

Although traditionally, the phenomenon of infra-humanization has been seen as an aspect of intergroup essentialism, i.e. perceiving others as qualitatively different from one's own group, the results obtained by Haslam (2006) showed that it also operates on the individual level. Unfamiliar individuals who were not perceived in terms of group affiliation were also seen as less capable of experiencing exclusively human emotions.

The automatic and universal character of infra-humanization drew the researchers' attention to the significance of cognitive resources. This phenomenon is often interpreted in terms of attribution error. Abstract contents defining secondary emotions are less accessible and, consequently, more rarely attributed to outgroup members than to the in-group ones. The infra-humanization effect can be mitigated or even completely blocked in the condition of freely available cognitive resources and intentional activity (Leyens, Demoulin, Vaes, Gaunt, \& Paladino, 2007).

\section{Description of Current Research}

The aim of the current research was to verify the effect of perspective rotation and the role of "fixing" cognitive resources in the domain of social perception. The studies focused on the infra-humanization effect.

The results of our previous experimental research showed that activation of social perspec- tive taking by imitating a mimic expression of a person from the out-group significantly lowers infra-humanization in comparison with both the condition of mimicry inhibition and the control condition (Szuster \& Wojnarowska, 2016). The findings obtained proved the beneficial effect of social perspective taking. In the case when spatial perspective is assumed, however, we expected different effects. Although infra-humanization and mimicry are activated at a similar, automatic level, spatial perspective taking involves systematic processing along the "bottom-up" path and is effort-consuming. Also, one of its significant components is inhibition. On the other hand, however, research shows the importance of freely available cognitive resources in reducing the infra-humanization effect (Levens, Demoulin, Vaes, Gaunt, \& Paladino, 2007). It justifies the assumption that involvement of cognitive resources in the effort-consuming spatial perspective taking will tend to intensify the infra-humanization symptoms.

Therefore, we expected the involvement of cognitive resources in perspective rotation to increase infra-humanization: the automatic effect in social perception, secondary to the process of categorization.

The main hypothesis is as follows:

In the condition that requires the subject to take the partner's spatial perspective, that which is different from his/her own (experimental condition), the effect of infra-humanization of the partner increases, as compared to the condition where the partner's spatial perspective is the same as that of the subject (control condition).

In order to test that hypothesis, an adequate tool needed to be designed and verified. The first experiment aimed at verifying the method of activating spatial perspective taking.

The additional hypothesis is as follows:

In the condition that requires the subject to take the partner's spatial perspective, the one 
different from his/her own (experimental condition), the performance of assigned tasks is lower (slower times and greater number of errors), as compared to the condition where the partner's spatial perspective is the same as that of the subject's (control condition).

\section{Experiment 1}

\section{Materials and Method}

The purpose of the first experiment was to verify the method activating spatial perspective taking. We expected a difference in task performance between subjects in two conditions: 1) the condition requiring spatial perspective rotation (experimental condition); and 2 ) the condition where the partner's spatial perspective is the same as that of the subject (control condition). A dedicated software application inspired by Keysar and Epley's methodology was used (Epley, Morewedge, \& Keysar, 2004; Keysar et al., 2000). To test the hypothesis, a between-subject design was used.

\section{Participants}

Ninety-three participants took part in the trial (63 females and 30 males, aged $18-25$ years $M=$ $20.14, S D=1.59$ ), all of them applying for studies at the Faculty of Psychology. They were randomly assigned to the control $(n=46,32$ females and 15 males, aged $18-25$ years, $M=$ 20.26, $S D=1.87)$ and experimental conditions ( $n=47,32$ females and 15 males, aged $18-25$ years, $M=20.02, S D=1.28)$. The participants in both conditions were comparable in terms of age and gender. All the participants were recently admitted students of psychology at the Faculty of Psychology. They came to the Faculty to submit their documents after being accepted to study there. At that time, they were invited to participate in the experiment. Participation was voluntary. Participants received a small reward: a badge with the logo of the Faculty of Psychology. Prior to the analysis, outliers were excluded from the database: times of task completion under 1 second suggesting accidental mouse clicks and those above $50 \mathrm{sec}-$ onds that were likely due to the participant giving up on the task. Eventually, 86 participants were included in the analysis (58 females and 28 males).

\section{Operationalization of Variables}

The partner's spatial positioning was manipulated. A software application called Bookshelf was developed. It consists of about a dozen slides containing descriptions of the situational context, instructions and tasks. Participants were asked to imagine they were in a room in the middle of which stands a bookshelf with balls of various sizes, in different slots in the array, and that there was a partner whose instructions they would be following. The spatial location of the partner varied: 1) In the experimental condition, the partner stands at the opposite side of the bookshelf (facing the participant) and cannot see the contents of some of the shelves (slots in the array) as they are blocked from his view and remain visible only from the perspective of the participant (Figure $1) ; 2$ ) in the control condition, the partner stands next to the participant, at the same side of the bookshelf, and sees everything from the same perspective as that of the participant.

Participants were asked to move objects as directed by the partner, e.g., "I want the smallest ball moved to the top right shelf of the bookshelf'. The experiment consisted of two trials. In each trial there were 4 balls of different sizes in the array. The directions always referred to the "confounding" objects that, in the experimental condition, required adjustments of the participant's spatial perspective (e.g., the smallest ball placed on a shelf visible to the participant was blocked from the partner standing on 


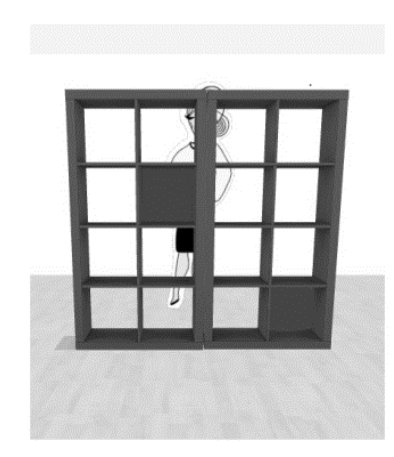

Figure 1 Experimental condition

the opposite side of the bookshelf [Figure 2]). In the experimental condition, the instruction for the task drew attention to the difference in the perspectives of the participant and partner of the interaction ("Remember that Alex is standing on the opposite side of the bookshelf and sees it differently"). Using a mouse, participants dragged selected objects to the slots indicated. The instructions and the aim of the task were comprehensible to the participants, according to the pilotage done prior to conducting the research.

Task performance was a dependent variable. The variable measures were:

- task completion time measured in seconds

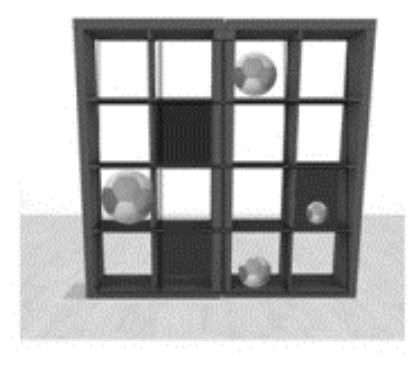

Figure 2 View of the bookshelf with balls
- accuracy of task performance (number of errors made by choosing a wrong object and/or a wrong slot to which the object was to be moved). One error of either of the two kinds (object/slot) was allowed in each of the two trials, so the total number of errors in the whole task ranged from 0 (no mistakes) to 4 (incorrect performance of the whole task)

\section{Procedure}

The study was anonymous and conducted individually. The experimenter invited individuals who showed up at the Faculty of Psychology at the University of Warsaw to sign up for the experiment. The study was conducted in a laboratory. Participants were randomly assigned to the control and experimental conditions. Consenting participants were told the true purpose of the study: to measure performance on a computer-simulated spatial task. Next, the experimenter started the application and left the room. The remaining instructions were given on the monitor screen. The task in each condition consisted of two trials. The indices were measured in the first trial; there were no practice tasks. At the end of the experiment, participants received a reward.

\section{Statistical Analysis}

Firstly, the differences in the number of errors in two conditions were examined using the Mann-Whitney U test. Next, similar analyses were done to establish differences in the distribution of error rates in two conditions for each type of an error (incorrect choice of a ball or space on the bookshelf). In order to assess which type of error (ball or bookshelf) was more frequent in experimental condition, the Wilcoxon-Sing test was used. Also, the comparison of completion times in two conditions was made, using the Mann-Whitney U test (distribution of dependent variable - completion 
time - deviated from normal). All data analyses were conducted in SPSS 24.

\section{Results}

The analysis revealed a greater number of errors in the experimental $(M d n=2$, mean rank $63.50)$ than in the control condition $(M d n=0$, mean rank 22.55), $U=44.00, p<.001, r=.897$. Overall, in the experimental condition, the overwhelming majority of participants performing the task committed one, two or three mistakes $(n=34)$, and 8 performed the entire task incorrectly. Only two participants in the experimental condition performed the entire task correctly. In the control condition, most participants made no mistakes $(n=40)$, with only two making some errors. The rates of errors in each condition are shown in Figure 3.
The analyses of differences in the distribution of error rates in two conditions for each type of error showed that both task performance parameters, the choice of an object and of a slot, were significantly differentiated between the two conditions. In the experimental condition, the number of errors was significantly greater than in the control condition. The manipulation effect was also present regardless of the measurement analyzed (trial $1 /$ trial 2). In Table 1, we present detailed results of the analyses.

In the experimental condition, there was a greater number of errors in ball choices than in slot choices. Participants were significantly less frequently aware of the fact that the ball they saw as the smallest was occluded from the partner standing on the opposite side of the book$\operatorname{shelf}(Z=-5.143, p<.001)$.

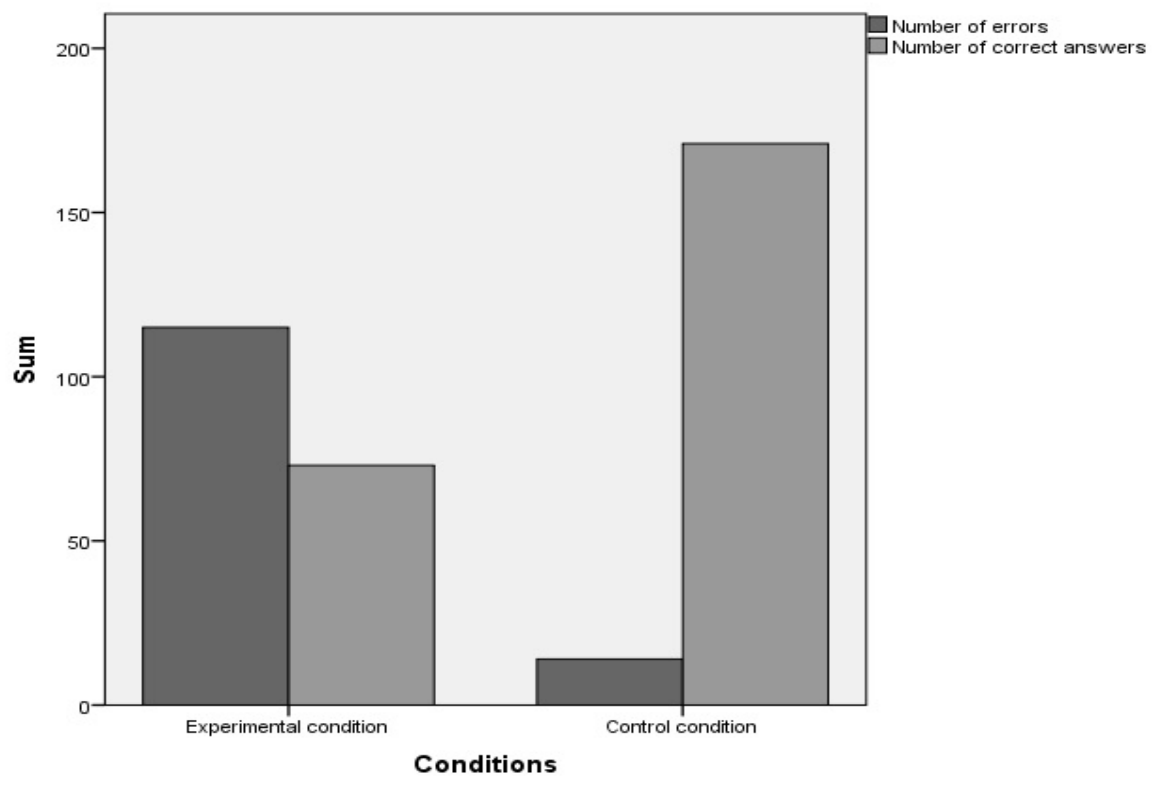

Figure 3 Number of errors and correct answers in experimental and control conditions 
Table 1 Comparison of number of errors in experimental and control condition

\begin{tabular}{lcccccc}
\hline & \multicolumn{2}{c}{$\begin{array}{c}\text { Experimental } \\
\text { condition }\end{array}$} & \multicolumn{2}{c}{ Control condition } & \multicolumn{2}{c}{$\begin{array}{c}\text { Comparison } \\
\text { between conditions }\end{array}$} \\
\cline { 2 - 7 } & \multicolumn{2}{c}{$\mathrm{n}=44$} & \multicolumn{2}{c}{$\mathrm{n}=42$} & U Mann test \\
\cline { 2 - 7 } & Median & $\begin{array}{c}\text { Mean } \\
\text { rank }\end{array}$ & Median & $\begin{array}{c}\text { Mean } \\
\text { rank }\end{array}$ & $\mathrm{U}$ & $\mathrm{P}$ \\
\hline $\begin{array}{l}\text { Total number of errors } \\
\text { Incorrect choice of a }\end{array}$ & 2 & 63.50 & 0 & 22.55 & 44.00 & 0.000 \\
ball & 63.00 & 0 & 23.07 & 66.00 & 0.000 \\
$\begin{array}{l}\text { Incorrect choice of a } \\
\text { space on the bookshelf }\end{array}$ & 0 & 50.18 & 0 & 36.50 & 630.00 & 0.000 \\
$\begin{array}{l}\text { Number of errors in } \\
\text { trial 1 }\end{array}$ & 1 & 62.77 & 0 & 23.31 & 76.00 & 0.000 \\
$\begin{array}{l}\text { Number of errors in } \\
\text { trial 2 }\end{array}$ & 1 & 63.55 & 0 & 22.50 & 42.00 & 0.000 \\
\hline
\end{tabular}

Analyses also demonstrated that the total completion time for the two tasks was significantly longer in the experimental condition than in the control $(U=670.50, p=.029, r=.237)$. The mean of the ranks for experimental condition was $49.26(M d n=18.43)$, while the mean rank for the control condition was $37.46(M d n=$ 16.79).

\section{Discussion}

The results confirmed our hypothesis: Accuracy in task performance operationalized as the choice of correct objects and slots varied significantly across conditions. Spatial perspective rotation produced a marked decrease in both measures of task performance. The time for completion proved longer in the condition requiring spatial perspective rotation. Furthermore, no differences were found between two trials for any of the performance aspects analyzed. The greatest challenge was to identify the correct object: to point out the one that was perceptually available to the partner.

The starting point for much of the research conducted within the paradigm described above was Keyser's concept of the role of shared knowledge in communication and mutual understanding (Keysar et al., 2000). According to that idea, shared knowledge diminishes the likelihood of considering a "non-shared" object and helps correct the egocentric error. In our study, however, that was not the case: participants committed surprisingly many errors in the perspective rotation condition. The present study, however, revealed a time effect: Subjects took longer to complete the task if they had to rotate perspective. The effect was significant only for the second trial, which may suggest that experience gained in the first trial led participants to involve more cognitive resources: to be more careful and take more time to complete the task. Still, the longer time taken by participants for the task in the second trial did not translate into improved accuracy. Previous research (Epley et al., 2004) has demonstrated that although both children and adults looked at the confounding objects with equal frequency, the latter corrected their reasoning significantly more often, which was enhanced by the lack of other factors requiring cognitive resources and motivation to perform the task ac- 
curately. Despite slight differences between the results obtained by Epley and Keysar and our findings, it turns out that the applied method is an apt operationalization of spatial perspective taking. Its efficiency as a task engaging cognitive resources was confirmed.

\section{Experiment 2}

\section{Method}

The purpose of the second experiment was to determine whether the overload of cognitive resources due to perspective rotation modifies the infra-humanization effect.

\section{Participants}

There were 80 participants ( 55 females and 25 males, aged $18-25$ years, $M=20.55, S D=2.14$ ) in the study, all newly admitted psychology students. Participation was voluntary. Participants received, as their only reward, a badge with the logo of the Faculty of Psychology. The participants were randomly assigned to the control ( $n=40,28$ females and 12 males, aged $18-25$ years, $M=20.5, S D=2.16)$ and experimental conditions ( $n=40,27$ females and 13 males, aged 18 - 25 years, $M=20.6, S D=2.16$ ). The participants in both conditions were comparable in terms of age and gender. No participants were excluded from the database.

\section{Operationalization of Variables}

Manipulation involved the spatial location of the partner. For that purpose, the software application Bookshelf was used. In the experimental condition, the partner was standing at the opposite side of the bookshelf, whereas in the control condition, he was standing at the same side as the participant. The participant's task was to move objects around on the virtual array as directed by their partner.
To assess the level of infra-humanization, the emotions scale (Leyens, 2000) adapted by Mirosławska \& Kofta (2007) was used. It consists of a list of 28 emotions that differ in terms of mood (positive $v s$. negative) and complexity (primary $v s$. secondary). Participants were asked to rate on a 7-point scale how often they experienced a given emotion (where 1 means "I never feel like this" and 7 means "I feel this way very often").

The subjects rated their own emotions ("Me") first and then, after the Bookshelf task, they rated the emotions of their partner ("Other"), whose directions they followed while performing the task.

\section{Procedure}

The study was anonymous and conducted individually. Participants were randomly assigned to the control and experimental conditions and were told that the purpose of the study was to check how people perceive themselves, others and the surrounding world. When the standard verbal consent was obtained, the experimenter primed the participants to think about the self by referring to the membership in the group of students of the Faculty of Psychology. He congratulated participants on having been accepted, referred to the prestige of the university, and gave them a badge with the logo of the Faculty of Psychology. The purpose was to trigger self-categorization as a university student. After the conversation, participants completed the "Me" version of the emotions scale while already in the lab. Next, they did the tasks in the Bookshelf application in one of two conditions, completing two trials. At the end, they completed the emotion scale, this time rating the person who was giving them directions in the computer application. The instruction for the scale noted that the person had decided not to go to university and was now working. The criterion for categorization was then the 
affiliation with a students' group vs. with a group of non-studying working people, while the higher status of the students' group was highlighted.

\section{Statistical Analysis}

Firstly, to asses manipulation efficacy, differences in task completion times and the number of errors in two conditions were examined, using the Mann-Whitney U test. Distribution of task completion time deviated from normal, and therefore a non-parametrical test was used. Next, in order to test the hypothesis regarding the impact of perspective rotation upon attribution of the valence of primary and secondary emotions to the self and the other person, a 2 (object: the self/the other) x 2 (emotion type: primary/secondary) $\times 2$ (condition: experimental/control) mixed ANOVA was calculated, with the first two factors varying within the subjects, and the last factor between the subjects. All data analyses were conducted in SPSS 24.

\section{Results}

Manipulation efficacy control. Analyses showed differences in task completion time between two conditions $(U=564.50, p=.023, r=$ $.255)$. When the partner was at the opposite side of the bookshelf(experimental condition), participants took more time to follow his directions (mean rank 46.39, $M d n=18.43$ ) than in the control condition, where he was standing next to them (mean rank 34.61, $M d n=16.80$ ). The analysis of errors revealed significant differences in the number of errors made, depending on the spatial positioning of the partner $(U=$ $42.00, p<.001, r=.894)$. Significantly more errors were made in the experimental condition than in the control one.

Hypothesis testing. Two main effects were revealed: object type and emotion type. Object type (the self vs. the other) was found to significantly differentiate the valence of attributed emotions $\left[F(1,78)=5.47, p=.022, \eta_{p}^{2}=.07\right]$; a higher valence of all emotions was attributed to the self $(M=4.28, S D=.63)$ than to the other $(M=4.11, S D=.59)$. Types of attributed emotions turned out to be significantly differentiated $\left[F(1,78)=7.15, p=.009, \eta_{p}^{2}=.08\right]$. A markedly higher number of secondary emotions was attributed $(M=4.28, S D=.61)$, compared with the primary ones $(M=4.12, S D=$ $.57)$.

As expected, the results showed a significant interaction among conditions, types of emotions and objects $\left[\mathrm{F}(1,78)=4.08, p=.047, \eta_{p}^{2}=\right.$ .05 . In the experimental condition, participants attributed a lower valence of secondary emotions to the other $(M=4.15, S D=.54)$ than to the self $(M=4.45, S D=.88), p=.024$, yet there was no difference between the self and the other as far as primary emotion attribution is concerned. Thus, in the experimental condition we can see a clear effect of infra-humanization. Additionally, in the control condition, we found a significant difference in the attribution of primary emotions: Participants attributed a higher valence of primary emotions to the self $(M=$ 4.14, $S D=.74)$ than to the other $(M=3.92, S D=$ $.68), p=.05$, and, at the same time, no difference in the attribution of secondary emotions was revealed. The results are shown in Figures 4 and 5 .

\section{Discussion}

The results of the study confirmed the predictions of the hypothesis. The requirement of perspective rotation increased the effect of infra-humanization. The result can be explained in terms of cognitive overload: The spatial perspective rotation task placed such high demands on cognitive resources that the perception of the partner's emotions (especially secondary ones, the content of which is less avail- 


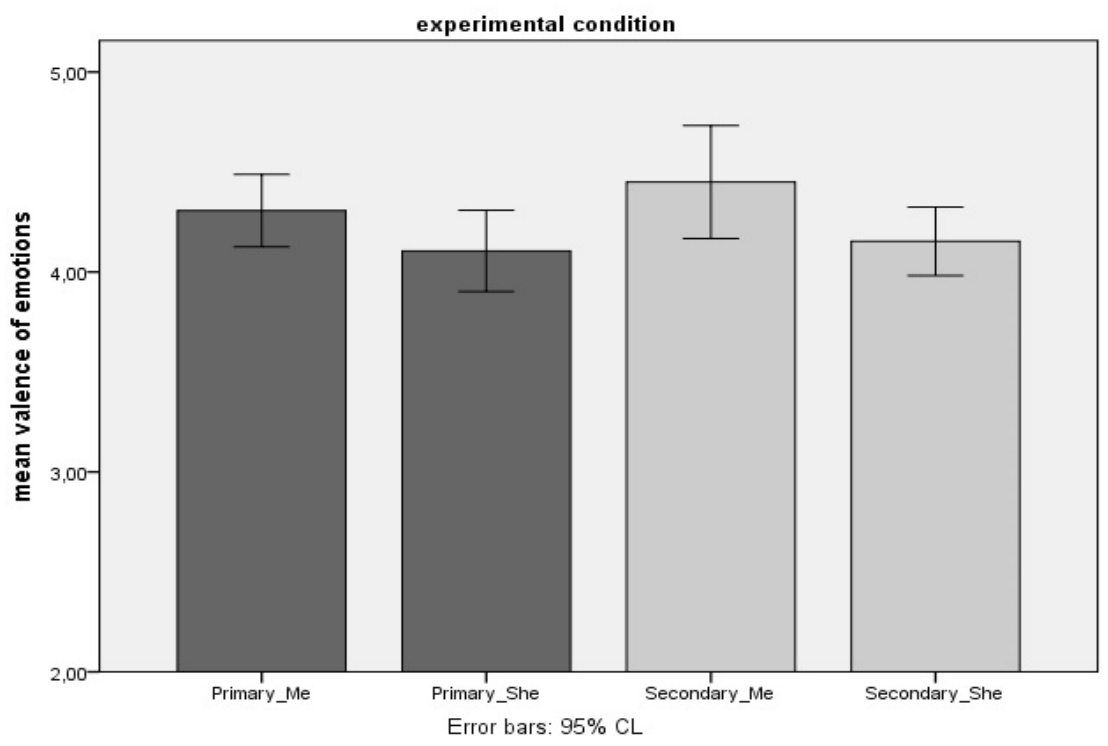

Figure 4 Mean valence of primary and secondary emotions attributed to the self and to the other in the experimental condition

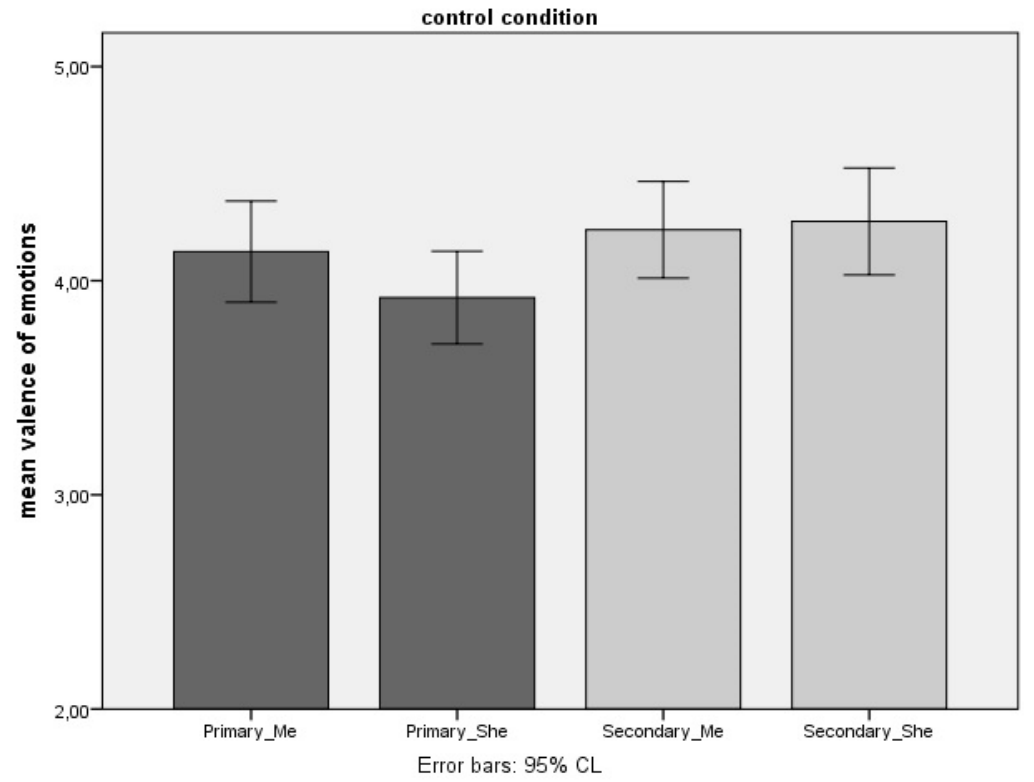

Figure 5 Mean valence of primary and secondary emotions attributed to the self and to the other in the control condition 
able) was to a greater extent simplified and distorted. Thus, the presence of cognitive load can absorb available cognitive resources and disturb the processes of social cognition (reduce the ability to reflect more reflective forms of behavior). Limiting available cognitive resources decreases the chance of activating a reflective strategy that could overcome the automatic effects of infra-humanization. The results obtained are consistent with the research by Baumeister and colleagues (Baumeister, Vohs, \& Tice, 2007), who showed that cognitive overload leads to a higher number of cognitive errors and increases the likelihood of falling prey to social influence traps.

No infra-humanization effect occurred under the control condition. There was no distortion between the perception of one's own and the other person's secondary emotions, which occurred in the experimental condition. However, there was a difference in the perception of primary emotions: The respondents attributed more primary emotions to themselves than to the other person.

It is worth recalling that such difference in perception of secondary emotions is the essence of the infra-humanization effect. The difference in the perception of primary emotions revealed under the control condition does not, therefore, change the basic interpretation of the obtained results. Rather, it indicates that in the context of freely available cognitive resources, the perception of another person changes not only within the scope of attribution of secondary, but also primary, emotions. There is a specific "humanization" of the other person, expressed not only in the lack of difference in the attribution of secondary emotions, but also in attributing to the other person less frequent experiencing of primary emotions. Freely available cognitive resources are conducive to building a more complex image of another person.

\section{General Discussion}

The findings from both studies are consistent and support the hypothesized relationships. The two experiments confirmed that spatial rotation required to assume the perspective of another person places demands on cognitive resources and, as a consequence, decreases cognitive task performance and affects the perception of others. The first study was mainly a replication to confirm the validity of a novel software-based method. The obtained results confirmed that the Bookshelf method can be used as an effective tool for cognitive resource overload manipulation. The findings from the second study suggest that the consequences of spatial perspective taking affect social attitudes by skewing the perception of other people's emotionality. Increased infra-humanization in the spatial perspective rotation condition indicates that a simplified and biased attribution of a poorer ability to experience uniquely human emotions to others may be cognitively determined. The overload of cognitive resources in the first task was found to undoubtedly intensify the infra-humanization effect. It confirms both the automatic and nonspecific nature of the phenomenon, which, in this case, is not the result of a specific or generalized history of interactions. It is the effect of a limited opportunity to use complex, abstract concepts (secondary emotions) that play a key role in infra-humanization. The secondary emotions are of an abstract nature, and it was the development of the neocortex that made experiencing them possible. Hence, they constitute one of the attributes of humanity (Leyens, 2000). The complex and reflective nature of secondary emotions has been empirically proven by the findings that indicated that priming based on words related to such emotions increased the effectiveness of attention-processing con- 
trol in Anti-saccade tests (Hallett, 1978) and mitigated the interference effect in the Stroop test (Imbir \& Jarymowicz, 2013).

A change in spatial perspective requires attention focus: as a new, non-self-evident task, it may then generate certain deficits that are manifested in the availability and ease of operating abstract categories that actually define secondary emotions. The source of cognitive overload present in performing tasks requiring rotation of egocentric perspective was necessary, firstly, to inhibit the primal, egocentric response and then to modify it (Epley et al., 2004). The consequences of such cognitive resource mobilization were also evidently manifested in the second task, in the form of attributing simplified emotional characteristics to another person (in comparison to more accessible self-characteristics) (Markus, 1977). This confirms a certain inertia of cognitive processes and suggests that the availability of resources or attention allocation does not alter quickly from one task to the next. Adjustment takes time. These kinds of effects, which show increased manifestations of various automatisms caused by a prior overload of cognitive resources, have been confirmed in numerous studies (Brycz, 2004; Chen, Schechter, \& Chaiken; 1996; Keysar, 2007; Lin, Keysar, \& Epley, 2010; Brown-Schmidt, 2009; Wardlow, 2013). On the other hand, depletion of cognitive resources leads to activation of the automatic level of regulation, increases stereotyped functioning (Bargh, 1997/1999), is associated with relying on superficial arguments in constructing attitudes (Petty \& Cacioppo, 1986; Johnson \& Eagly, 1989) and amplifies preference for personal, self-related criteria of value judgments of others (Rutkowska \& Szuster, 2011).

Lastly, there comes a question concerning the code through which perspective taking is activated. While the benefits of social perspective comprise stereotyped expressions reduction and enhancement of communication and ne- gotiation efficacy (Galinsky, Maddux, Gilin, \& White, 2008), the results of our research show that the spatial aspect of perspective taking has the opposite effect. In the studies that have demonstrated positive consequences of perspective taking, the social code was activated. Furthermore, there was a consistency between the activated code and the contents of the recorded attitudes. Priming cues referring to social perspective taking enhanced the availability of others, thereby generating a reflective information-processing mode. By contrast, the rotation of spatial perspective in the described research activated a different type of code, devoid of social content. It focused on the formal aspect of the perspective, the one not associated with social significance, and helped to activate simplified, categorical content.

The studies described have certain limitations. Firstly, we cannot rule out that a different task placing demands on cognitive resources without engaging perspective rotation would bring similar results. Therefore, the results gained may not be specific exclusively to spatial perspective taking.

Some questions concerning the type of errors made by the participants in the Bookshelf application may arise as well. There were two types of mistakes in the Bookshelf application: wrong shelf choice and wrong ball choice. While the first error includes mainly spatial rotation - as in a "mirror reflection" (which, as the experiment showed, was easier for the participants), the cognitive background for the second type of errors might be more complex. It may include processes such as rotating the perspective, deciding on the linear order of the balls (which one is the smallest/biggest) and taking into consideration the perceptive restrictions (hidden shelves). Our findings do not identify which of these processes is responsible for the ball errors. Additional experiments need to be conducted in order to make a definite conclusion. 
There are also a few methodological issues that should be addressed in future research. The participants did not undergo a training session during the spatial perspective taking task, which could have influenced the difference between time reactions in the first and the second trial in the experimental condition. The design of the method was carefully drafted - two trials ensured that the cognition load effect would be a mere effect of the actual perspective taking, not a training effect. In future research it would be necessary to expand the paradigm with additional trials, so as to have a complete view of the perspective taking abilities and to measure the effect of learning.

Gender-specific effects should also be discussed here. The sample was not balanced across gender - there were more women than men. Longitudinal research has proven that girls in adolescence have higher levels of perspective taking than boys (Van der Graaf et al., 2014), which is consistent with the assumption that girls precede boys by about two years in intellectual and social cognitive functioning during adolescence (Silberman \& Snarey, 1993). The effect of gender on perspective taking in adults is less clear, however - women score higher than men on self-reported empathy, but the results are not as reliable when a different measure is used (Eisenberg \& Lennon, 1983). For future implications, it would be necessary to balance the sample across gender.

Undoubtedly, however, our findings revealed differences in the consequences of activating social versus spatial perspective taking in interpersonal situations and may serve as an important clue for researchers seeking factors that mitigate negative attitudes toward others.

\section{References}

Bargh, J. A. (1997/1999). Automatyzmy dnia powszedniego. Czasopismo Psychologiczne, 5(3), 209-256.
Barlińska, J., Szuster, A., \& Winiewski, M. (2013). Cyberbullying among adolescents: Role of the communication medium, form of violence and empathy. Journal of Communication \& Applied Social Psychology, 23(1), 37-51. doi: 10.1002/casp.2137

Barlińska, J., Szuster, A., \& Winiewski, M. (2015). The role of short- and long-term cognitive empathy activation in preventing cyberbystander reinforcing cyberbullying behavior. Cyberpsychology, Behavior and Social Networking, 18(4), 241-244. doi: 10.1089/cyber.2014.0412

Baumeister, R. F., Vohs, K. D., \& Tice, D. M. (2007). The strength model of self-control. Current Directions in Psychological Science, 16(6), 351-355.

Boccato, G., Cortes, B. P., Demoulin, S., \& Leyens, J. P. (2007). The automaticity of infra-humanization. European Journal of Social Psychology, 37(5), 987999.

Brown-Schmidt, S. (2009). The role of executive function in perspective taking during online language comprehension. Psychonomic Bulletin \& Review, 16(5), 893-900.

Brycz, H. (2004). Trafność spostrzegania wlasnych $i$ cudzych zachowań. Gdańsk: Uniwersytet Gdański.

Chalmers J. B., \& Townsend, R. (1990). The effect of training in social perspective taking on socially maladjusted girls. Child Development, 61(1), 178190. doi: $10.1111 /$ j.1467-8624.1990.tb02770.x

Chandler, M. J. (1973). Egocentric and antisocial behaviour. The assessment and training of social and perspective-taking skills. Developmental Psychology, 9(3), 326-332. doi: 10.1037/h0034974

Chen, S., Shechter, D., \& Chaiken, S. (1996). Getting at the truth or getting along: Accuracy-versus impression-motivated heuristic and systematic processing. Journal of Personality and Social Psychology, 71(2), 262-275.

Cialdini, R. B., Brown, S. L., Lewis, B. P., Luce, C., \& Neuberg, S. L. (1997). Reinterpreting the empathyaltruism relationship: When one into one equals oneness. Journal of Personality and Social Psychology, 73(3), 481 .

Crisp, R. J., \& Hewstone, M. (2006). Multiple social categorization: Processes, models and applications. New York: Psychology Press.

Davis, M. H., Conklin, L., Smith, A., \& Luce, C. (1996). Effect of perspective taking on the cognitive representation of persons: A merging of the Self and Other Journal of Personality and Social Psychology, 70(4), 713-726.

Demoulin, S., Leyens, J. P., Paladino, M. P., RodriguezTorres, R., Rodriguez-Perez, A., \& Dovidio, J. (2004). Dimensions of "uniquely" and "nonuniquely" human emotions. Cognition and Emotion, 18(1), 71-96. 
Drogosz, M., Bilewicz, M., \& Kofta, M. (Ed.) (2012). Poza stereotypy: Dehumanizacja i esencjalizm $w$ postrzeganiu grup spolecznych. Warszawa: Scholar. Eisenberg, N., \& Lennon, R. (1983). Sex differences in empathy and related capacities. Psychological Bulletin, 94(1), 100-131. doi: 10.1037/0033-2909. 94.1 .100

Ekman, P. (1992). An argument for basic emotions. Cognition \& Emotion, 6(3-4), 169-200.

Epley, N., Morewedge, C. K., \& Keysar, B. (2004). Perspective taking in children and adults: Equivalent egocentrism but differential correction Journal of Experimental Social Psychology 40(6), 760-768. doi: $10.1016 /$ j.jesp.2004.02.002

Erle, T. M., \& Topolinski, S. (2015). Spatial and empathic perspective-taking correlate on a dispositional level. Social Cognition, 33(3), 187-210.

Fiske, S. T., Taylor, S. E., Etcoff, N. L., \& Laufer, J. K. (1979). Imaging, empathy, and causal attribution. Journal of Experimental Social Psychology, 15(4), 356-377.

Flavell, J. H., Green, F. L., Flavell, E. R., Watson, M. W., \& Campione, J. C. (1986). Development of knowledge about the appearance-reality distinction. Monographs of the Society for Research in Child Development, 51(1), 1-87.

Galinsky, A. D., Maddux, W. W., Gilin, D., \& White, J. B. (2008). Why it pays to get inside the head of your opponent: The differential effects of perspective taking and empathy in negotiations. Psychological Science, 19(4), 378-384. doi: 10.1111/ j.1467-9280.2008.02096.x.

Galinsky, A. D., \& Moskowitz, G. B. (2000). Perspective-taking: Decreasing stereotype expression, stereotype accessibility and in-group favoritism. Journal of Personality and Social Psychology, 78(4), 708-724. doi: 10.1037/0022-3514.78.4.708

Gehlbach, H. (2004). A new perspective on perspective taking: A multidimensional approach to conceptualizing an aptitude. Educational Psychology Review, 16(3), 207-234.

Hallett, P. (1978). Primary and secondary saccades to goals defined by instructions. Vision Research, 18(10), 1279-1296. doi: 10.1016/0042-6989(78) 90218-3

Haslam, N. (2006). Dehumanization: An integrative review. Personality and Social Psychology Review, 10 (3), 252-64. doi: 10.1207/s15327957pspr1003 4.

Hamilton, A. F. D. C., Brindley, R., \& Frith, U. (2009). Visual perspective taking impairment in children with autistic spectrum disorder. Cognition, 113(1), 3744.

Hegarty, M., \& Waller, D. (2004). A dissociation between mental rotation and perspective-taking spatial abilities. Intelligence, 32(2), 175-191.
Imbir, K., \& Jarymowicz, M. (2013). The effect of automatic vs. reflective emotions on cognitive control in antisaccade tasks and the emotional Stroop test. Polish Psychological Bulletin, 44(2), 137-146. doi: $10.2478 / \mathrm{ppb}-2013-0016$

Johnson, B. T., \& Eagly, A.H. (1989). Effects of involvement on persuasion: A meta-analysis. Psychological Bulletin, 106(2), 290-314. doi: 10.1037/ 0033-2909.106.2.290

Kessler, K., \& Rutherford, H. (2010). The two forms of visuo-spatial perspective taking are differently embodied and subserve different spatial prepositions. Frontiers in Psychology, 1, 213.

Kessler, K., \& Thomson, L. A. (2010). The embodied nature of spatial perspective taking: Embodied transformation versus sensorimotor interference. Cognition, 114(1), 72-88.

Keysar, B. (2007)/ Communication and miscommunication: The role of egocentric processes. Intercultural Pragmatics, 4(1), 71-84.

Keysar, B., Barr, D. J., Balin, J. A., \& Brauner, J. S. (2000). Taking perspective in conversation: The role of mutual knowledge in comprehension Psychological Science, 11(1), 32-38 doi: 10.1111/14679280.00211

Kozhevnikov, M., \& Hegarty, M. (2001). A dissociation between object manipulation spatial ability and spatial orientation ability. Memory \& Cognition, 29(5), 745-756.

Lakoff, G., \& Johnson, M. (1980). Metaphors we live by. Chicago: The University of Chicago Press.

Leyens, J. (2000). The emotional side of prejudice: The attribution of secondary emotions to ingroups and outgroups. Personality and Social Psychology Review, 4(2), 186-197. doi: 10.1207/S15327957 PSPR0402 06

Leyens, J., Demoulin, S., Vaes, J., Gaunt, R., \& Paladino, M. P. (2007). Infra-humanization: The wall of group differences. Social Issues and Policy Review, 1(1), 139-172. doi: 10.1111/j.1751-2409.2007.00006.x

Leyens, J., Rodriguez-Perez, A., Rodriguez-Torres, R., Gaunt, R., Paladino, M. P., Vaes, J., \& Demoulin, S. (2001). Psychological essentialism and the differential attribution of uniquely human emotions to ingroups and outgroups. European Journal of Social Psychology, 31(4), 395-411. doi: 10.1002/ ejsp. 50

Libby, L. K., \& Eibach, R. P. (2011). Visual perspective in mental imagery: A representational tool that functions in judgment, emotion, and self-insight. In M. P. Zanna, \& J. M. Olson (Eds.), Advances in Experimental Social Psychology, Vol. 44, (pp. 185245). San Diego: Academic Press.

Lin, S., Keysar, B., \& Epley, N. (2010). Reflexively mindblind: Using theory of mind to interpret behav- 
ior requires effortful attention. Journal of Experimental Social Psychology, 46(3), 551-556.

Markus, H. R. (1977). Self-schema and processing information about the self. Journal of Personality and Social Psychology, 35(2), 63-78. doi: 10.1037/ 0022-3514.35.2.63

Mirosławska, M., \& Kofta, M. (2007). Zjawisko infrahumanizowania obcych: Wstępny test hipotezy generalizacji Ja. Psychologia Społeczna, 2, 52-65.

Michelon, P., \& Zacks, J. M. (2006). Two kinds of visual perspective taking. Perception \& Psychophysics, 68(2), 327-337.

Moll, H., \& Tomasello, M. (2007). How 14- and 18month-olds know what others have experienced. Developmental Psychology, 43(2), 309-317. doi: 10.1037/0012-1649.43.2.309

Paladino, M. P., Leyens, J. P., Rodriguez, R., Rodriguez, A., Gaunt, R., \& Demoulin, S. (2002). Differential association of uniquely and non uniquely human emotions with the ingroup and the outgroup. Group Processes \& Intergroup Relations, 5(2), 105-117.

Piaget, J. (1955). The child's construction of reality. London: Routledge and Kegan.

Piaget, J., \& Inhelder, B. (1956). The child's concept of space. London: Routledge \& Paul.

Petty, R. E., \& Cacioppo, J. (1986). The elaboration likelihood model of persuasion. Advances in Experimental Social Psychology, 19, 124-203. doi: 10.1007/978-1-4612-4964-1_1

Rodríguez-Torres, R., Leyens, J. P., Pérez, A. R., Rodriguez, V. B., Quiles del Castillo, M. N., Demoulin, S., \& Cortés, B. (2005). The lay distinction between primary and secondary emotions: A spontaneous categorization?. International Journal of Psychology, 40(2), 100-107.

Ruby, P., \& Decety, J. (2001). Effect of subjective perspective taking during simulation of action: A PET investigation of agency. Nature Neuroscience, 4(5), 546-550.

Ruby, P., \& Decety, J. (2003). What you believe versus what you think they believe: A neuroimaging study of conceptual perspective-taking. European Journal of Neuroscience, 17(11), 2475-2480.

Ruby, P., \& Decety, J. (2004). How would you feel versus how do you think she would feel? A neuroimaging study of perspective-taking with social emo- tions. Journal of Cognitive Neuroscience, 16(6), 988-999.

Rutkowska, D., \& Szuster, A. (2003). Operowanie pojęciami wartościującymi w warunkach wzbudzenia automatycznego vs. refleksyjnego systemu wartościowania u osób o różnym stopniu ukształtowania standardów pozaosobistych. Studia Psychologiczne, 41(2), 107-130.

Silberman, M. A., \& Snarey, J. (1993). Gender differences in moral development during early adolescence: The contribution of sex-related variations in maturation. Current Psychology, 12(2), 163-171. doi:10.1007/BF02686821

Sroufe, L. A. (1979). The coherence of individual development: Early care, attachment, and subsequent developmental issues. American Psychologist, 34(10), 834-841.

Storms, M. D. (1973). Videotape and the attribution process: Reversing actors' and observers' points of view. Journal of Personality and Social Psychology, 27(2), 165-175. doi: 10.1037/h0034782

Surtees, A. D. R., Apperly, I. A., \& Samson, D. (2013). The use of embodied self-rotation for visual and spatial perspective-taking. Frontiers in Human Neuroscience, 7, 698.

Szuster, A., Gniewek, A., \& Wojnarowska, A. (2016). Społeczne przyjmowanie perspektywy - o egzocentryzmie i empatii jako dyspozycyjnych przejawach procesu i ich związkach ze spostrzeganiem innych. Psychologia Spoleczna, 4(39), 21-35.

Szuster, A., \& Wojnarowska, A. (2016). The influence of mimicry on the reduction of infra-humanization. Frontiers in Psychology, 7. doi: 10.3389/fpsyg.2016. 00975

Vaes, J., \& Paladino, M. P. (2010). The uniquely human content of stereotypes. Group Processes \& Intergroup Relations, 13(1), 23-39.

van der Graaf, J., Branje, S., de Wied, M., Hawk, S., van Lier, P., \& Meeus, W. (2014). Perspective taking and empathic concern in adolescence: Gender differences in developmental changes. Developmental Psychology, 50(3), 881-888. doi: 10.1037/ a0034325.

Wardlow, L. (2013). Individual differences in speakers' perspective taking: The roles of executive control and working memory. Psychonomic Bulletin \& Review, 20(4), 766-772. 